\title{
EXPERIMENTAL STUDY ON THE CRITERIA AND MECHANISM OF SPALLATION IN AN ALUMINIUM ALLOY*
}

\author{
Shen Letian, Zhao Shida, Bai Yilong and Luo Limin \\ Laboratory of Non-linear Mechanics of Contınuous Media. Instıtute of Mechanics, \\ Chınese Academy of Sciences. Beııng 100080, P R.China
}

(Received 20 June 1990; in retsised form 3 August 1991)

\begin{abstract}
Summary - In this paper, a damage function defined by the residual strength of spalled specimens of an aluminium alloy is given to characterize the spallation of the material. Based on this function a simple method for continuously describing the spallation may be developed. Stress wave profiles showing the signal of spallation were successfully obtained with carbon gauges. Microscopic observations of the spalled aluminium alloy specimens reveal that the nucleation of spallation initiates from cracking of the second phase particles. Spallation is a process of crack nucleation. growth and coalescence to final. complete disintegration.
\end{abstract}

\section{INTRODUCTION}

Fracture of solids due to shock waves, i.e. the spallation of materials, results from tensile stress impulses formed by the reflection of compression waves at the interfaces adjacent to low impedance media. For example, ballistic effects, high velocity impact, high energy rate forming or energy deposition of high energy particle beams can produce this kind of loading impulse. Spallation is a transient fracture process involving simultaneous activation of a large number of microcracks or microvoids. The period of fracture is of the same order of magnitude as the stress duration. Therefore, it is impossible to treat the spallation process with the theory of conventional fracture mechanics in which only single or finite cracks are considered. In general, there are two approaches to the study of spallation [1-3]. One is called the cumulative damage model and the other is named the nucleation and growth model of cracks. The former uses a macroscopic method to describe the spallation process, by which the material under tensile impulse is considered to be spalled while the average value of a certain property of the microcrack or microvoid, such as the number or the volume, exceeds a given level. The definition of the damage level in the model is qualitative and controlled by several parameters to be determined. It is effective for the description of experimental results or for the application of design criteria in engineering. The nucleation and growth model of the crack is a statistic method. The type of damage, ductile or brittle, is determined through experiments and the rule of nucleation and growth of microcracks or microvoids is obtained by correlation of the statistical data of microcracks or microvoids from observation with the stress history in material. The parameters, describing microcracks or microvoids, are involved in the constitutive equation, and the process of dynamic fracture can thus be simulated with a code for wave propagation. In this respect, the important work of Curran and co-workers $[2,4,5]$ should be mentioned. Besides, Davison et al. [6], Cochran and Banner [7], Johnson [8], Dremin and Molodets [9] and Xing Xiusan [10] etc. also investigated along this line. Recently, Bai et al. [11] proposed one-dimensional statistical modelling of damage evolution in spallation using the mechanics of continuous media, and preliminary results were obtained.

In this paper, the spallation of an aluminium alloy was characterized with a damage function defined by the residual strength of the specimens. By means of the damage function

*The project was supported by the National Natural Science Foundation of China. 
the feature of spallation can thus be continuously described. The stress history profiles in spalled specimens recorded by carbon piezoresistant stress gauges agreed quite well with that of Shockey et al. [5], Rosenberg et al. [12] and Isbell and Christman [13]. Based on the experimental results, the mechanism of the whole damage process in spallation involving nucleation, growth and coalescence of microcracks was discussed.

\section{TEST MATERIAL AND EXPERIMENTAL TECHNIQUE}

The specimens were taken from a rolled sheet of an aluminium alloy similar to 2219-T6 Al. The physical and mechanical properties of the material are shown in Table 1. The yield strength appeared to be insensitive to strain rate in our split Hopkinson pressure bar experiments over strain rates from $10^{2}$ to $10^{3} \mathrm{~s}^{-1}$. We recognize that in the impacts we achieve strain rates of about $10^{5} \mathrm{~s}^{-1}$, so the assessment on insensitivity may be inappropriate.

To establish a spallation criterion for the aluminium alloy, a series of plate impact tests under one-dimensional strain condition were made at room temperature. All the experiments were carried out with a $101 \mathrm{~mm}$ bore single-stage light gas gun [14]. The schematic arrangement for the experiments is shown in Fig. 1.

Specimens were machined into circular plates $70 \mathrm{~mm}$ in diameter, with different thicknesses from 2 to $10 \mathrm{~mm}$. The thickness orientation of the specimen coincided with that of the rolled sheet of the aluminium alloy. Either symmetrical or unsymmetrical impacts, i.e. the target and flyer of the same or different materials, were taken in the experiments. In order to obtain a high amplitude stress impulse with relatively short duration, a nickel impactor of $0.1 \mathrm{~mm}$ thickness and a molybdenum flyer with a thickness of $0.3 \mathrm{~mm}$ were used in the unsymmetrical impact tests. The Hugoniot equations of the aluminium alloy, nickel and molybdenum are $U_{\mathrm{s}}=5827+1.89 U_{\mathrm{p}}[15], U_{\mathrm{s}}=4581+1.463 U_{\mathrm{p}}$ [16] and $U_{\mathrm{s}}=5124+1.233 U_{\mathrm{p}}[16]$, respectively, where $U_{\mathrm{s}}$ is the shock velocity and $U_{\mathrm{p}}$ is the particle velocity. After impact, the specimens were soft recovered with a specially designed catcher to prevent any secondary damage. Then, the recovered specimens were inspected with an ultrasonic detector to locate initially the spalled positions. The specimens were finally sectioned along the diameter into two parts for residual ultimate tensile strength tests and microscopic observations, respectively.

Table 1. The physical and mechanical PROPERTIES OF THE ALUMINIUM ALLOY

\begin{tabular}{lc}
\hline Density & $2.83 \mathrm{~g} / \mathrm{cm}^{3}$ \\
Tensile yield strength & $333 \mathrm{MPa}$ \\
Tensile ultimate strength & $449 \mathrm{MPa}$ \\
Elastic modulus & $81 \mathrm{GPa}$ \\
Speed of sound & $5827 \mathrm{~m} / \mathrm{s}$ \\
\hline
\end{tabular}

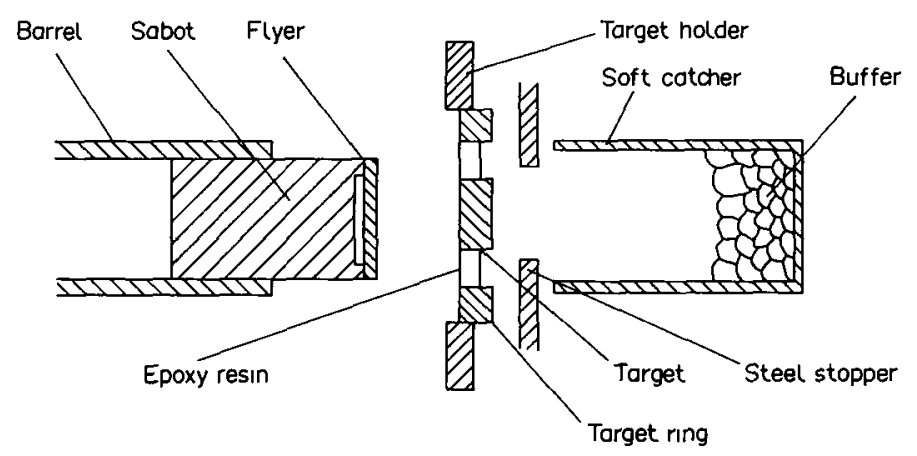

Fig 1. Plate impact apparatus for spall study. 
A damage function is defined as

$$
F=1-\sigma_{\mathrm{r}} / \sigma_{\mathrm{b}}
$$

where $\sigma_{\mathrm{r}}$ is the experimentally determined residual ultimate tensile strength of the spalled specimen $[17,18]$ and $\sigma_{\mathrm{b}}$ is the ultimate tensile strength of the virgin aluminium alloy. $F$ varies between 0 and 1. Therefore, the damage function $F$ can be used to investigate the spallation characteristics continuously. The residual tensile strengths of some impacted specimens are shown in Table 2. It is seen from Table 2 that the residual strengths for those specimens with thicknesses of 10 and $8 \mathrm{~mm}$, only, were measured. Because it was difficult to machine the thinner specimens into tensile coupon, the values $F$ of the specimens with thicknesses of 5 and $4 \mathrm{~mm}$ were estimated in the following way. According to our observations, there is a one-to-one correspondence of the value $F$ and the microscopical measure of damage $1^{\prime} / 1$, i.e. ratio of the total length of cracks in a certain section of a specimen to the length of the section [18]. Therefore, when the characteristics of cracks $1^{\prime} / 1$ in the thinner specimens were similar to those in the thicker specimens examined on the same condition, $F$ for the thinner specimens was considered to be the same as that of the thicker specimens. In this paper, only those data corresponding to $F \sim 1 / 3,1 / 2$ and 1 were chosen for illustration.

The spallation criterion proposed by Tuler and Butcher [3] and Butcher et al. [19] may be rewritten as follows:

$$
\left(\sigma / \sigma_{0}-1\right)^{n}\left(T-T_{0}\right)=K
$$

where $\sigma$ is the nominal tensile stress, $T$ is the duration of $\sigma, K, n, T_{0}$ and $\sigma_{0}$ are constants dependent on the damage function $F$. In Eqn (2) there are four constants to be determined. Firstly, the method of cut and try was used. $T_{o}$ was found to be small enough that it can be neglected as compared with $T$. Then Eqn (2) becomes:

$$
\left(\sigma / \sigma_{0}-1\right)^{n} \Delta T=K \text {. }
$$

The deduced value of $\sigma_{0}$ was around $450 \mathrm{MPa}$, which was considered to be a suitable value, just near the ultimate strength of the virgin material. After $T_{0}$ and $\sigma_{0}$ are fixed the least squares fitting procedure can be greatly simplified.

Spallation criteria of the aluminium alloy for different $F(F \sim 1 / 3,1 / 2$ and 1$)$ are fitted from the experimental data (Tables 3-5) obtained through symmetrical impacts.

$$
\begin{array}{ll}
(\sigma / 450-1)^{1.171} \Delta T=1.798 & \text { for } F=1 / 3 \\
(\sigma / 450-1)^{1.381} \Delta T=2.438 & \text { for } F=1 / 2 \\
(\sigma / 450-1)^{1.795} \Delta T=3.853 & \text { for } F=1 .
\end{array}
$$

\begin{tabular}{|c|c|c|c|c|c|}
\hline \multirow{2}{*}{$\begin{array}{l}\text { Test } \\
\text { No. }\end{array}$} & \multirow{2}{*}{$\begin{array}{c}\text { Impact } \\
\text { velocity } \\
V_{1} \\
(\mathrm{~m} / \mathrm{s})\end{array}$} & \multicolumn{2}{|c|}{$\begin{array}{l}\text { Thickness of } \\
\text { specimen } \\
(\mathrm{mm})\end{array}$} & \multirow{2}{*}{$\begin{array}{c}\text { Residual } \\
\text { strength } \\
(\mathrm{MPa})\end{array}$} & \multirow[b]{2}{*}{$F$} \\
\hline & & Flyer & Target & & \\
\hline $84-74$ & 85.2 & 5.04 & 10.02 & 439 & 0.022 \\
\hline $84-75$ & 100.6 & 5.04 & 10.04 & 316 & 0.296 \\
\hline $84-98$ & 108.9 & 5.03 & 10.08 & 305 & 0.321 \\
\hline $84-13$ & 122.2 & 5.00 & 10.00 & 217 & 0.517 \\
\hline $83-11$ & 136.8 & 5.00 & 10.00 & 25 & 0.944 \\
\hline $84-77$ & 121.4 & 3.96 & 8.02 & 259 & 0.423 \\
\hline $84-71$ & 122.4 & 4.02 & 8.06 & 284 & 0.367 \\
\hline $84-70$ & 139.0 & 4.04 & 8.04 & 210 & 0.532 \\
\hline $84-112$ & 148.2 & 3.98 & 7.96 & 40 & 0.911 \\
\hline
\end{tabular}

TABLE 2. THE RESIDUAL TENSILE STRENGTHS OF IMPACTED SPECIMENS 
TABLE 3. EXPERIMENTAL RESULTS OF GROUP 1 , FOR $F=1 / 3$

\begin{tabular}{lccccccc}
\hline & $\begin{array}{c}\text { Impact } \\
\text { velocity }\end{array}$ & \multicolumn{2}{c}{$\begin{array}{c}\text { Thickness of } \\
\text { specimen } \\
\text { Test }\end{array}$} & $\begin{array}{c}V_{1} \\
(\mathrm{~m} / \mathrm{s})\end{array}$ & $\begin{array}{c}\text { Duration } \\
\text { of } \sigma\end{array}$ & \multicolumn{2}{c}{$\begin{array}{c}\text { Nominal tensile stress } \\
\sigma(\mathrm{MPa})\end{array}$} \\
No. & Target & $\begin{array}{c}\Delta T \\
(\mu \mathrm{s})\end{array}$ & $\begin{array}{c}\text { Experimental } \\
\text { results }\end{array}$ & Prediction & $\begin{array}{c}\text { Error } \\
(\%)\end{array}$ \\
\hline $84-98$ & 108.9 & 5.03 & 10.08 & 1.741 & 914 & 913 & 0.13 \\
$84-71$ & 122.4 & 4.02 & 8.06 & 1.393 & 1029 & 1010 & 1.90 \\
$84-62$ & 160.6 & 2.40 & 5.00 & 0.835 & 1359 & 1316 & 3.12 \\
$84-88$ & 176.9 & 1.92 & 3.94 & 0.669 & 1500 & 1497 & 0.21 \\
\hline
\end{tabular}

TABLE 4. EXPERIMENTAL RESULtS OF GROUP 2, FOR $F=1 / 2$

\begin{tabular}{|c|c|c|c|c|c|c|c|}
\hline \multirow{3}{*}{ Test } & \multirow{3}{*}{$\begin{array}{c}\text { Impact } \\
\text { velocity } \\
V_{1} \\
(\mathrm{~m} / \mathrm{s})\end{array}$} & \multirow{2}{*}{\multicolumn{2}{|c|}{$\begin{array}{l}\text { Thickness of } \\
\text { specimen } \\
\text { (mm) }\end{array}$}} & \multirow{3}{*}{$\begin{array}{l}\text { Duration } \\
\text { of } \sigma \\
\qquad \Delta T \\
(\mu \mathrm{s})\end{array}$} & \multicolumn{3}{|c|}{$\begin{array}{c}\text { Nomınal tensıle stress } \\
\sigma(\mathrm{MPa})\end{array}$} \\
\hline & & & & & \multirow{2}{*}{$\begin{array}{l}\text { Experimental } \\
\text { results }\end{array}$} & \multirow[b]{2}{*}{ Prediction } & \multirow{2}{*}{$\begin{array}{l}\text { Error } \\
(\%)\end{array}$} \\
\hline & & Flyer & Target & & & & \\
\hline $84-13$ & 122.2 & 5.00 & 10.00 & 1.733 & 1028 & 1026 & 0.13 \\
\hline $84-70$ & 139.0 & 4.04 & 8.04 & 1.358 & 1146 & 1137 & 0.76 \\
\hline $84-10$ & 176.1 & 2.46 & 4.96 & 0.856 & 1494 & 1410 & 5.58 \\
\hline $84-90$ & 187.4 & 1.94 & 3.94 & 0.676 & 1592 & 1589 & 0.18 \\
\hline
\end{tabular}

TABle 5. EXPERIMENTAL RESULtS OF GROUP 3, FOR $F=1$

\begin{tabular}{|c|c|c|c|c|c|c|c|}
\hline \multirow{3}{*}{$\begin{array}{l}\text { Test } \\
\text { No. }\end{array}$} & \multirow{3}{*}{$\begin{array}{c}\text { Impact } \\
\text { velocity } \\
V_{1} \\
(\mathrm{~m} / \mathrm{s})\end{array}$} & \multirow{2}{*}{\multicolumn{2}{|c|}{$\begin{array}{l}\text { Thickness of } \\
\text { specimen } \\
(\mathrm{mm})\end{array}$}} & \multirow{3}{*}{$\begin{array}{l}\text { Duration } \\
\text { of } \sigma \\
\qquad \Delta T \\
(\mu \mathrm{s})\end{array}$} & \multicolumn{3}{|c|}{$\begin{array}{c}\text { Nominal tensile stress } \\
\sigma(\mathrm{MPa})\end{array}$} \\
\hline & & & & & \multirow{2}{*}{$\begin{array}{l}\text { Experimental } \\
\text { results }\end{array}$} & \multirow[b]{2}{*}{ Prediction } & \multirow{2}{*}{$\begin{array}{c}\text { Error } \\
(\%)\end{array}$} \\
\hline & & Flyer & Target & & & & \\
\hline $83-11$ & 136.8 & 5.00 & 10.00 & 1.735 & 1153 & 1152 & 0.10 \\
\hline $84-112$ & 148.2 & 3.98 & 7.96 & 1.382 & 1251 & 1247 & 0.35 \\
\hline $84-73$ & 181.0 & 2.52 & 5.00 & 0.839 & 1536 & 1502 & 2.20 \\
\hline $84-87$ & 193.4 & 1.92 & 3.96 & 0.670 & 1645 & 1643 & 0.13 \\
\hline
\end{tabular}

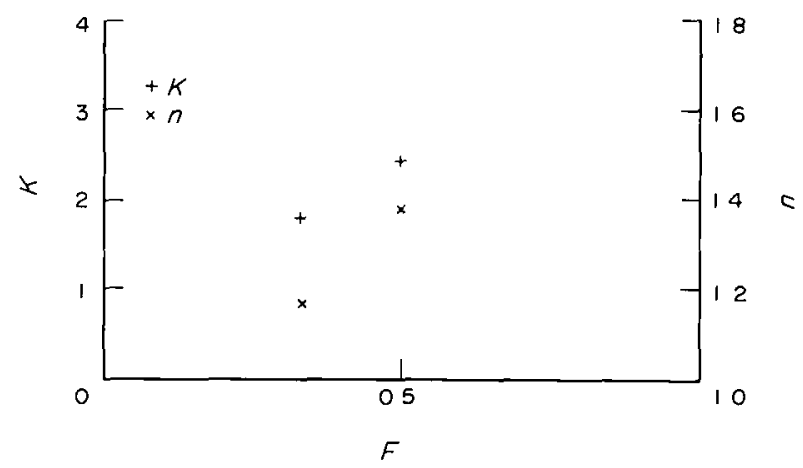

FIG 2. The variation of $K$ and $n$ with $F$.

Figure 2 shows the variations of $K$ and $n$ with $F[18]$ from which the relations of $K$ and $n$ to $F$ can be fitted. Then, Eqn (3) becomes :

$$
\left(\sigma / \sigma_{0}-1\right)^{n(F)} \Delta T=K(F) .
$$

$K$ should be a measure of the necessary time for the corresponding damage level. But the implication of variation of $n$ with $F$ is not clarified yet. Figures 3-4 are metallographic sections of spalled specimens for different $F$ values. 


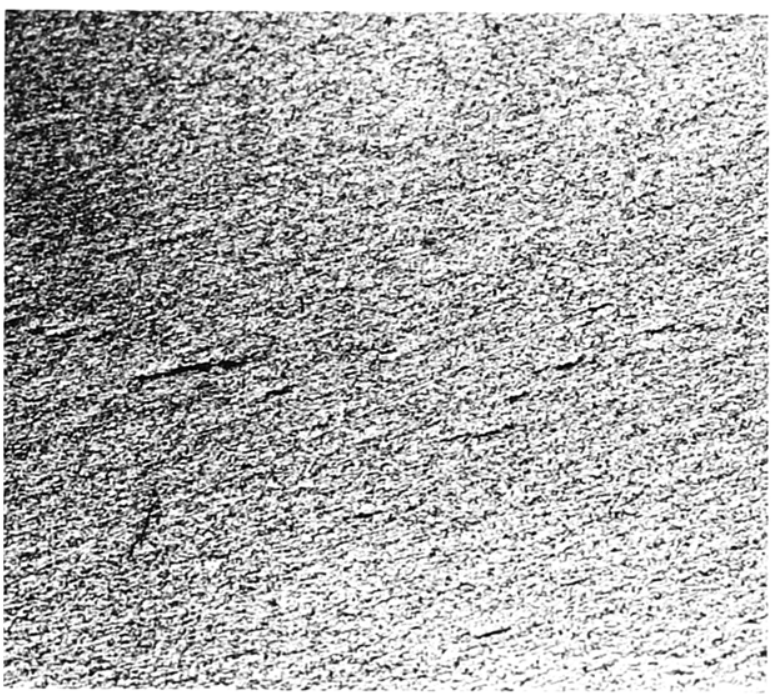

FIG 3. Crack feature of specimen with $F=1 / 3$ magnification $\times 50$.

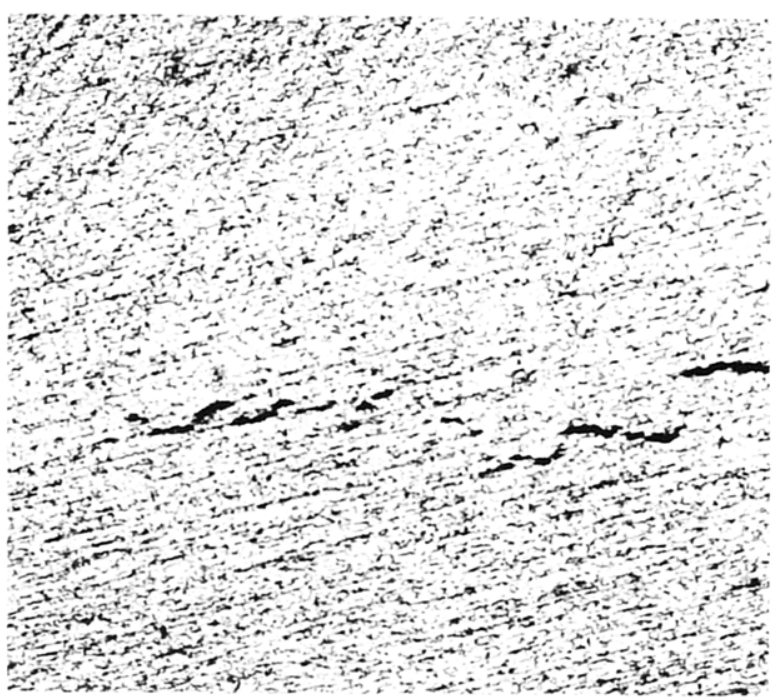

Fig 4. Crack feature of specimen with $F=1 / 2$ magnification $\times 50$.

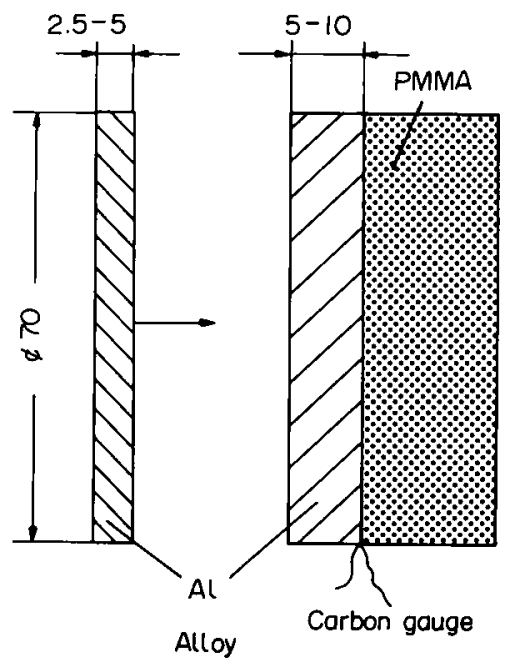

(a)

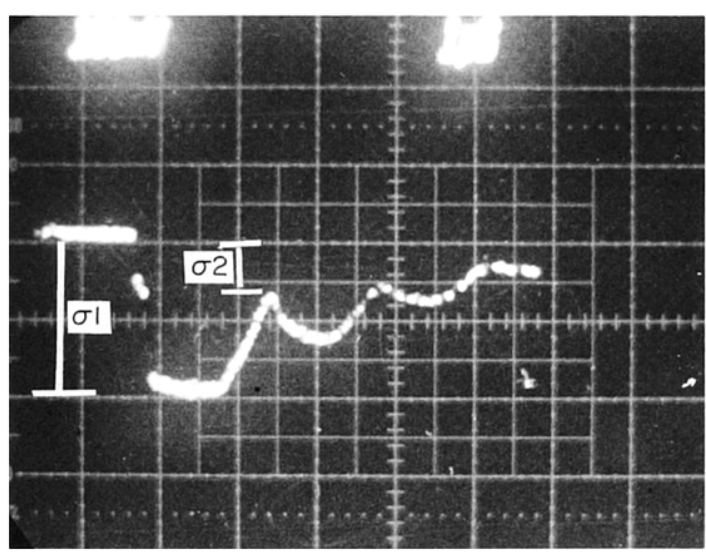

(b)

FIG 5. Arrangement of stress measurement in spallation test and a typical stress-time history in a spalled specimen.

Figure 5(a) shows the arrangement for the measurement of the stress profile in spallation tests. Figure $4(\mathrm{~b})$ is a typical stress-time history in spelled specimen recorded with a carbon sensor at the interface between an aluminium alloy target and a PMMA disk. It shows clearly the Hugoniot elastic limit (HEL), the loading plateau and the signals of spallation in Fig. 5(b). It is interesting to notice that the stress differences between the first maximum points $\sigma_{1}$ and the first minimum points $\sigma_{2}$ in the stress profiles are roughly constant in spite of the impact velocity and stress duration shown in Table 6. This may indicate a property which relates to the spallation characteristics of the material. The HEL for the aluminium alloy taken from the carbon gauge readings are also listed in Table 6. 


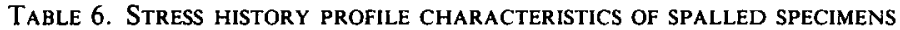

\begin{tabular}{|c|c|c|c|c|c|c|c|}
\hline \multirow{2}{*}{$\begin{array}{l}\text { Test } \\
\text { No. }\end{array}$} & \multirow{2}{*}{$\begin{array}{l}\text { Impact } \\
\text { velocity } \\
V_{1}(\mathrm{~m} / \mathrm{s})\end{array}$} & \multicolumn{2}{|c|}{$\begin{array}{c}\text { Thickness } \\
(\mathrm{mm})\end{array}$} & \multirow{2}{*}{$\begin{array}{c}\text { HEL } \\
\text { (MPa) }\end{array}$} & \multirow{2}{*}{$\begin{array}{c}\sigma_{1} \\
(\mathrm{MPa})\end{array}$} & \multirow{2}{*}{$\begin{array}{c}\sigma_{2} \\
(\mathrm{MPa})\end{array}$} & \multirow{2}{*}{$\begin{array}{l}\sigma_{1}-\sigma_{2} \\
(\mathrm{MPa})\end{array}$} \\
\hline & & Flyer & Target & & & & \\
\hline $85-52$ & 325.7 & 4.94 & 9.90 & 804 & 2059 & 955 & 1104 \\
\hline $84-114$ & 368.2 & 3.96 & 8.02 & 775 & 2148 & 1083 & 1065 \\
\hline $84-115$ & 340.4 & 3.94 & 8.07 & 766 & 1997 & 945 & 1052 \\
\hline $85-55$ & 512.6 & 2.38 & 4.92 & 720 & 2562 & 1580 & 982 \\
\hline
\end{tabular}

\section{MICROSCOPIC OBSERVATIONS AND DISCUSSIONS ON THE MECHANISM OF INCIPIENT SPALLATION}

\section{Microscopic aspects of the aluminium alloy}

Microscopic observations were carried out with a Polyvar Optic Microscope and a S-750 SEM. In the initial state, there are a large number of second phase particles ( $\theta$-phase) distributed in the $\alpha$ solid solution matrix. The number of second phase particles with size larger than $2 \times 2 \mu \mathrm{m}$ is about 900 per square millimeter (counted with a SEM), and the $\theta$ phase exists as a strengthening phase in the alloy. Microhardness of the matrix and the second phase particles were measured with a Hanemann tester. The average microhardness of the matrix is $154 \mathrm{Hv}$ and that of the $\theta$ phase is $324 \pm 83 \mathrm{Hv}$ which is apparently higher than the matrix's. These particles are of different sizes and various shapes, but all have a larger dimension along the rolling direction, shown in Fig. 6 . The initial grain size is given in Table 7.

\section{General illustration for spallation of the aluminium alloy}

Specimens impacted by stress pulses with different amplitudes and durations were examined with an optical microscope and a SEM. The results are as follows.

(a) The spallation damage of the aluminium alloy seems to be in the form of a brittle crack on the sectioned surface.

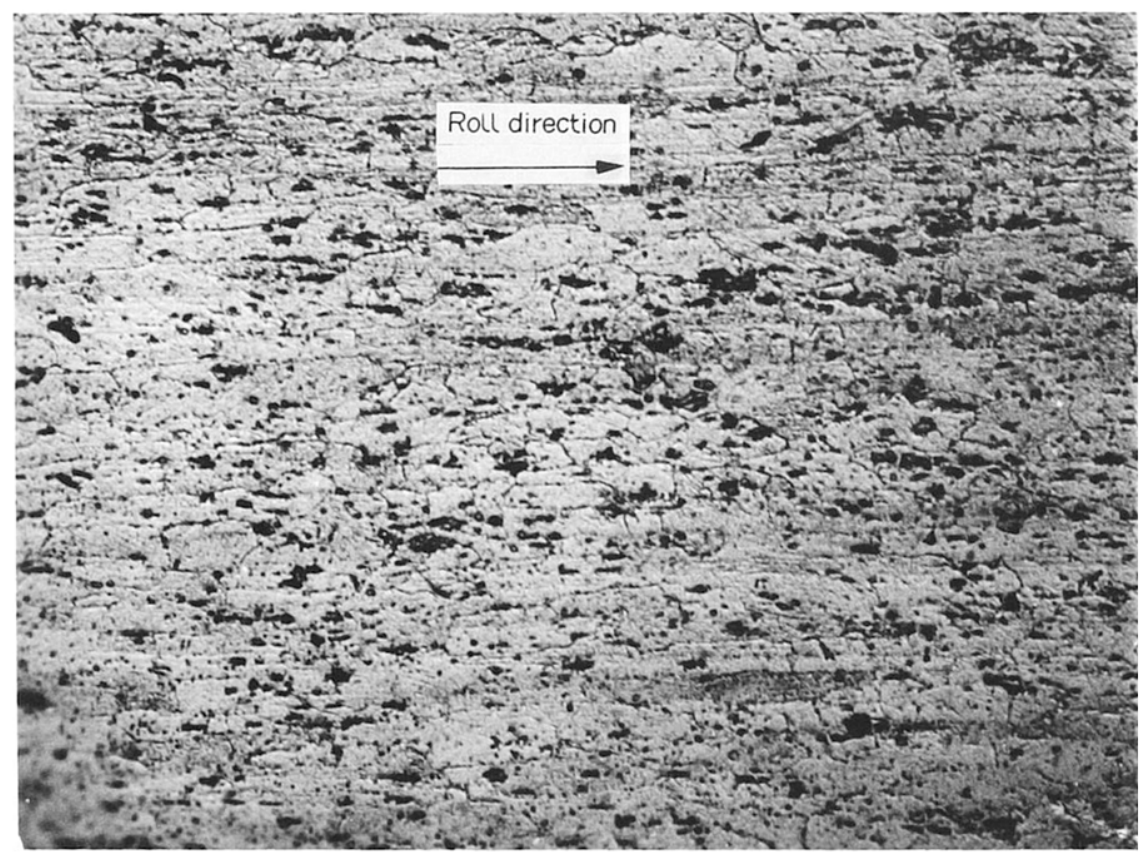

FIG 6. Metallograph showing the grains of the aluminium alloy (magnification $\times 100$ ). 
TABle 7. INITIAL GRain SIZE OF THE ALUMiNiUM alloy

\begin{tabular}{lcc}
\hline Direction & Along rolling direction & $\begin{array}{c}\text { Perpendicular to } \\
\text { rolling direction }\end{array}$ \\
\hline Total number of grains measured & 13 & 50 \\
Average grain size $(\mathrm{mm})$ & 0.027 & 0.010 \\
\hline
\end{tabular}

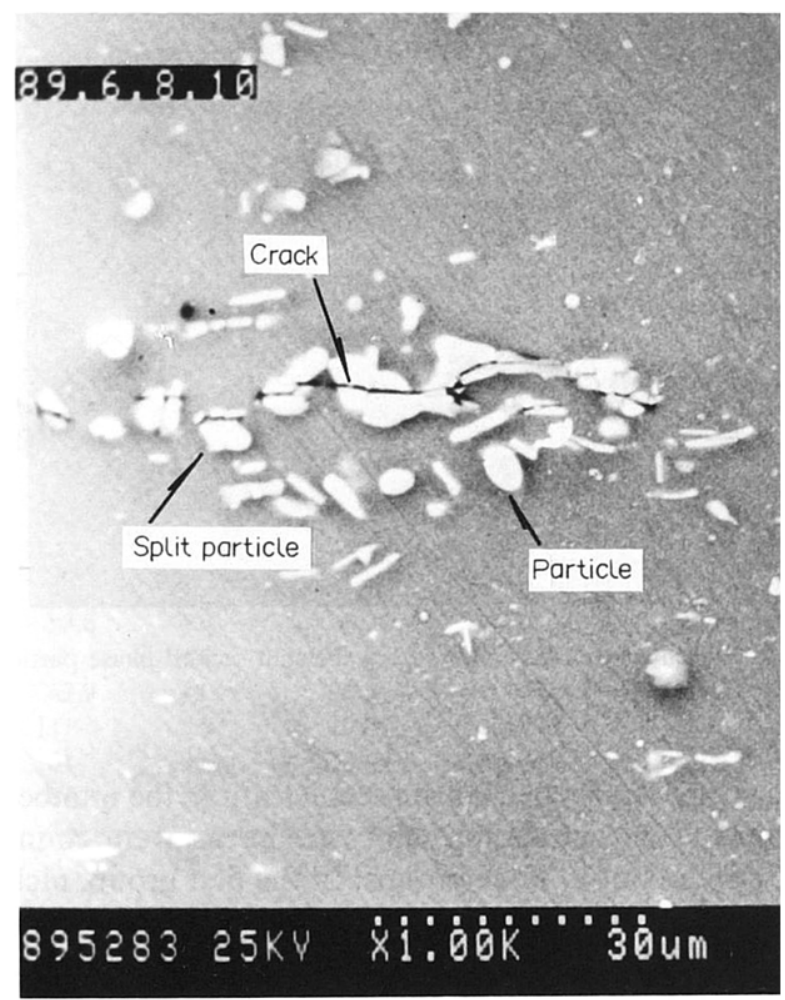

FIG 7. The nucleation, growth and coalescence of microcracks.

(b) The damage process involves nucleation, growth and coalescence of a large number of microcracks into macrocracks until complete disintegration, as shown in Fig. 7.

(c) Nearly all of the nucleations of the microcracks initiate at the second phase particles themselves, and those larger particles are more easy to crack. The initial extending or linking up of the microcracks is the crack propagation from the second phase particles into the matrix, or the connection of cracks between two nearby split particles as shown in Fig. 8.

(d) Cracks are distributed over a range of certain thickness. They are roughly parallel to each other and perpendicular to the direction of the tensile stress. In the macrocrack stage of spallation, cracks are connected from adjacent planes and therefore step cracks are developed, Fig. 7.

\section{Discussion of the mechanism of nucleation}

Nearly all cracks in this material during impact nucleate from splitting of second phase particles, and large particles are more easy to split than the small ones. This is quite different from that in the quasistatic, creep or fatigue tests, in which fractures originate from the soft matrix. 


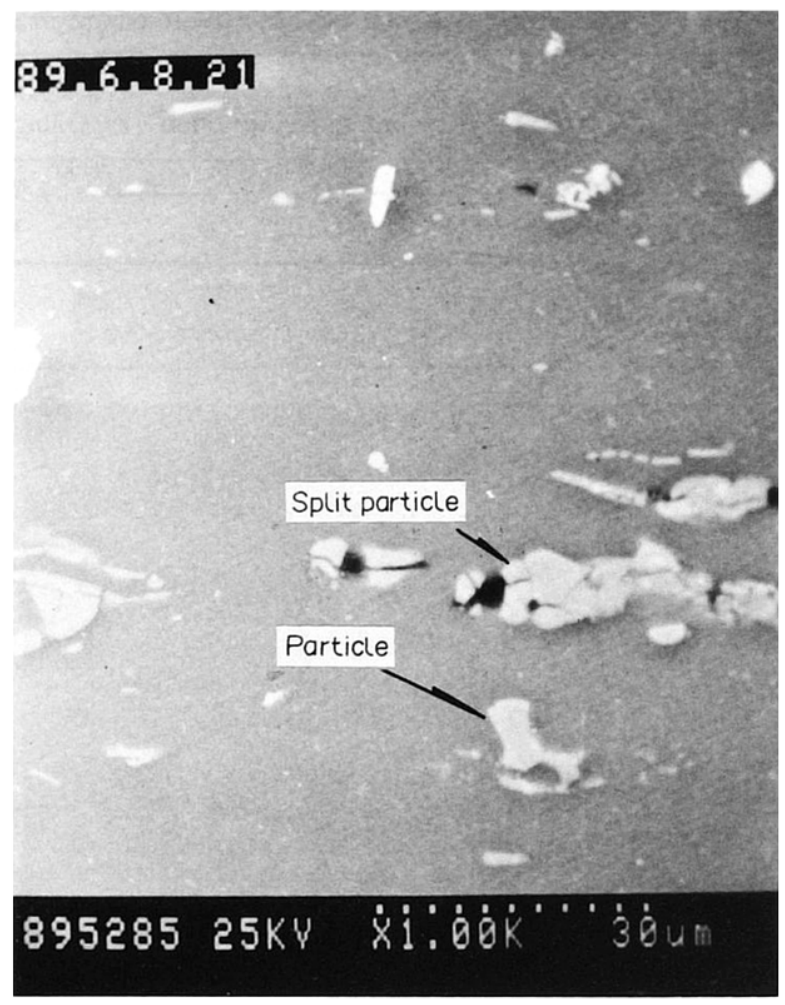

Fig 8. Nucleation of microcracks from the split second phase particles.

For further investigation on the mechanism of nucleation, the number of cracked second phase particles in the spalled aluminium alloy specimens were counted under a SEM. Statistical work was carried out in three groups. In the first group, nickel flyers of $0.1 \mathrm{~mm}$ in thickness and aluminium alloy targets of $5 \mathrm{~mm}$ in thickness were used. $0.3 \mathrm{~mm}$ thick molybdenum flyers and $5 \mathrm{~mm}$ thick aluminium alloy targets were taken in the second group. In the third group, both flyers and targets were the aluminium alloy with thickness 2-5 mm and 4-10 mm, respectively. The statistical results of groups 1,2 and 3 are shown in Tables 8,9 and 10, respectively. The tensile stresses and stress durations in the tables are estimated from the known Hugoniot relations of the target materials and the measured impact velocity $V_{\mathrm{i}}$. The unloading waves in both target and flyer are assumed to be elastic in the estimation. In addition, the counting of cracked particles was performed on a

TABle 8. Statistical RESUlts With $0.1 \mathrm{~mm}$ Ni impactor AND $5 \mathrm{~mm}$ Al alloy TARGET

\begin{tabular}{|c|c|c|c|c|c|}
\hline \multirow[b]{2}{*}{$\begin{array}{l}\text { Test } \\
\text { No. }\end{array}$} & \multirow{2}{*}{$\begin{array}{c}\text { Impact } \\
\text { velocity } \\
V_{\mathbf{i}} \\
(\mathrm{m} / \mathrm{s})\end{array}$} & \multicolumn{2}{|c|}{ Tensile stress } & \multirow{2}{*}{$\begin{array}{l}\text { Number of } \\
\text { cracked } \\
\text { particles } \\
\left(\mathrm{mm}^{-2}\right)\end{array}$} & \multirow{2}{*}{$\begin{array}{c}\text { The smallest } \\
\text { cracked particle } \\
\text { size } \\
(\mu \mathrm{m} \times \mu \mathrm{m})\end{array}$} \\
\hline & & $\begin{array}{l}\text { Amplitude } \\
\text { (MPa) }\end{array}$ & $\begin{array}{c}\text { Duration } \\
\text { (ns) }\end{array}$ & & \\
\hline $88-7$ & 230 & 2375 & 113.8 & 0 & \\
\hline *88-2 & 400 & 3167 & 134.6 & 39 & $3 \times 4$ \\
\hline $88-6$ & 417 & 5112 & 145.4 & 52 & $2 \times 2$ \\
\hline $88-22$ & 489 & 6057 & 156.6 & 65 & $2 \times 3$ \\
\hline $88-36$ & 520 & 6476 & 161.4 & 123 & $2 \times 2$ \\
\hline $88-16$ & 521 & 6487 & 161.5 & 88 & $3 \times 4$ \\
\hline $88-35$ & 565 & 7082 & 168.1 & 100 & $2 \times 3$ \\
\hline $88-21$ & 593 & 7460 & 172.2 & 123 & $2 \times 2$ \\
\hline
\end{tabular}


Table 9. Statistical results With $0.3 \mathrm{~mm}$ Mo impactor and $5 \mathrm{~mm} \mathrm{Al}$ ALLOY TARGET

\begin{tabular}{|c|c|c|c|c|c|}
\hline \multirow[b]{2}{*}{$\begin{array}{l}\text { Test } \\
\text { No. }\end{array}$} & \multirow{2}{*}{$\begin{array}{c}\text { Impact } \\
\text { velocity } \\
V \\
(\mathrm{~m} / \mathrm{s})\end{array}$} & \multicolumn{2}{|c|}{ Tensile stress } & \multirow{2}{*}{$\begin{array}{l}\text { Number of } \\
\text { cracked } \\
\text { particles } \\
\left(\mathrm{mm}^{-2}\right)\end{array}$} & \multirow{2}{*}{$\begin{array}{c}\text { The smallest } \\
\text { cracked particle } \\
\text { size } \\
(\mu \mathrm{m} \times \mu \mathrm{m})\end{array}$} \\
\hline & & $\begin{array}{l}\text { Amplitude } \\
\text { (MPa) }\end{array}$ & $\begin{array}{l}\text { Duration } \\
\text { (ns) }\end{array}$ & & \\
\hline $87-126$ & 257 & 2133 & 234 & 48 & $3 \times 3$ \\
\hline $87-127$ & 260 & 2160 & 235 & 76 & $2 \times 3$ \\
\hline $87-124$ & 310 & 2588 & 243 & 158 & $2 \times 3$ \\
\hline $87-125$ & 310 & 2588 & 243 & 136 & $2 \times 2$ \\
\hline $88-1$ & 360 & 3021 & 252 & 164 & $2 \times 2$ \\
\hline *88-3 & 400 & 3370 & 258 & 203 & $2 \times 3$ \\
\hline
\end{tabular}

Table 10. Statistical results with Al alloy impactor and al alloy target

\begin{tabular}{|c|c|c|c|c|c|c|}
\hline \multirow{3}{*}{$\begin{array}{l}\text { Test } \\
\text { No. }\end{array}$} & \multirow{3}{*}{$\begin{array}{c}\text { Impact } \\
\text { velocity } \\
V_{1} \\
(\mathrm{~m} / \mathrm{s})\end{array}$} & \multirow{2}{*}{\multicolumn{2}{|c|}{$\begin{array}{l}\text { Thickness of specimen } \\
\qquad(\mathrm{mm})\end{array}$}} & \multicolumn{2}{|c|}{ Tensile stress } & \multirow{3}{*}{$\begin{array}{c}\text { Number of } \\
\text { cracked } \\
\text { particles } \\
\left(\mathrm{mm}^{-2}\right)\end{array}$} \\
\hline & & & & Amplitude & Duration & \\
\hline & & Impactor & Target & (MPa) & $(\mu \mathrm{s})$ & \\
\hline *84-97 & 159 & 2.0 & 4.0 & 1345 & 0.68 & 20 \\
\hline $88-49$ & 134 & 2.5 & 5.0 & 1125 & 0.85 & 26 \\
\hline $88-48$ & 149 & 2.4 & 4.5 & 1258 & 0.71 & 103 \\
\hline *88-44 & 153 & 2.5 & 5.0 & 1293 & 0.85 & 101 \\
\hline $88-50$ & 93.5 & 4.0 & 8.0 & 783 & 1.36 & 39 \\
\hline *82-185 & 108 & 4.0 & 8.0 & 906 & 1.36 & 71 \\
\hline $82-191$ & 63.9 & 4.0 & 8.0 & 532 & 1.36 & 0 \\
\hline$* 84-76$ & 111 & 5.0 & 10.0 & 932 & 1.70 & 18 \\
\hline $84-75$ & 101 & 5.0 & 10.0 & 843 & 1.70 & 8 \\
\hline $84-74$ & 85.2 & 5.0 & 10.0 & 712 & 1.70 & 0 \\
\hline
\end{tabular}

rectangular area of $10 \times 0.066 \mathrm{~mm}^{2}$ with its long side parallel to the surface of the target. In fact, this area is of approximately six viewing fields with $\times 250$ magnification and contains about 600 particles.

From the data in Tables $8-10$, it is seen that for a given impulse duration the higher the stress amplitude, the more the amount of cracked particles will be. While only a small number of particles are damaged, they are almost all large ones. The number of cracked small particles seems to increase with the increase of stress. The smallest size of cracked particle observed is $2 \times 2 \mu \mathrm{m}$. It does not mean that small particles should crack only after all the larger ones have split. Observations revealed that some particles, whether large or small, do still remain uncracked, regardless of the amplitude of the pulse load, even when macrocracks have been developed.

For a given impulse duration, there exists a threshold stress for nucleation. No crack nucleation occurs in particles, while stress is lower than the threshold value. The threshold stress increases sharply with the decrease in impulse duration. On the other hand, there is also a critical time (or threshold time) for nucleation for a certain stress amplitude. No crack nucleation can be seen in particles while stress duration is less than the critical value. Table 11 illustrates the least number of nucleated particles in the specimens loaded by the stress with different impulse durations (named the critical nucleation data). The data listed in Tables 8, 9 and 10 are also shown in Fig. 9 in the form of $N / \Delta T$ (nucleation rate) versus stress level [20]. It shows a possible nucleation threshold stress around $1 \mathrm{GPa}$ which happens to be coincident with the values of $\left(\sigma_{1}-\sigma_{2}\right)$ listed in Table 6 . In addition, Fig. 9 indicates the very high stress, as well as possible stress duration, dependence of the nucleation process.

Microscopic observations of the specimens illustrated in Tables 8-10 show that in those 
Table 11. Critical nucleation data

\begin{tabular}{lccc}
\hline $\begin{array}{l}\text { Test } \\
\text { No. }\end{array}$ & $\begin{array}{c}\text { Stress } \\
(\mathrm{MPa})\end{array}$ & $\begin{array}{c}\text { Duration of stress } \\
(\mu \mathrm{s})\end{array}$ & $\begin{array}{c}\text { Number of cracked particles } \\
\left(\mathrm{mm}^{-2}\right)\end{array}$ \\
\hline $88-2$ & 3167 & 0.134 & 39 \\
$87-126$ & 2133 & 0.234 & 48 \\
$88-49$ & 1125 & 0.850 & 26 \\
$88-50$ & 783 & 1.360 & 39 \\
$84-75$ & 843 & 1.700 & 8 \\
\hline
\end{tabular}

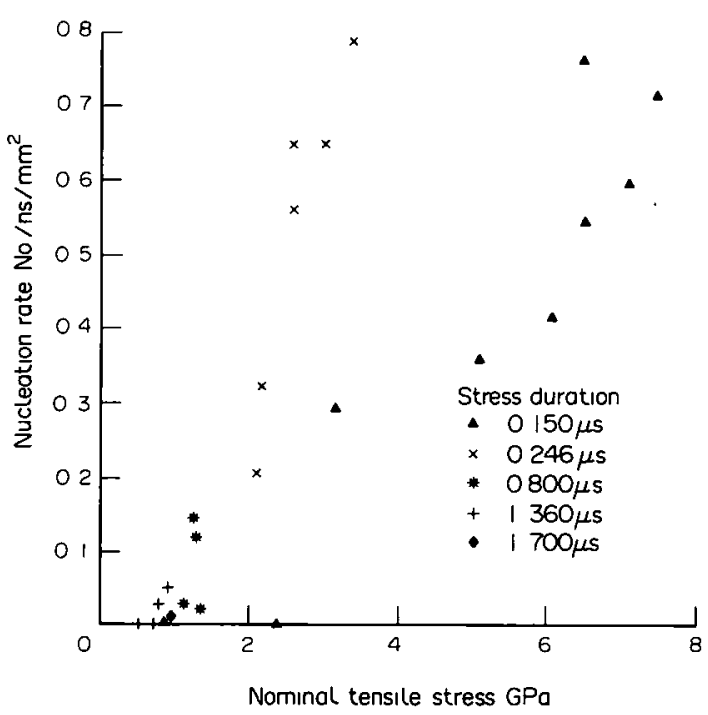

FIG 9. Nucleation rate versus stress level.

specimens with more cracked particles, microcracks are already connected, and macrocracks (about $1 \mathrm{~mm}$ long) exist in individual specimens marked with $*$ in Tables $8-10$, with the exception of 84-97. Under loading with a relatively large pulse duration, the stress amplitude needed where microcracks begin to link up is lower and the number of cracked particles is also smaller, except for sample 88-2. It is considered that for a definite stress, the longer the duration of the stress, its effects on growth and connection of microcracks will become more important. Provided coalescence of cracks occurs, it seems that the lower the stress amplitude, the less the number of cracked particles will be at the stage when microcracks begin to connect. At present, owing to the lack of available crack nucleation theory for describing the damage process in second phase particles, only a preliminary discussion could be given in this paper. In order to have a better understanding of this kind of crack nucleation, it is necessary to clarify the relationship among the crack of second phase particles, its geometric features, orientation, mechanical behaviour as well as the amplitude and the width of the applied stress, which needs further investigation.

\section{CONCLUSIONS}

(1) A damage function ( $F=1-\sigma_{\mathrm{r}} / \sigma_{\mathrm{b}}$ ) was defined by the residual strength of spalled specimens, and the spallation criteria of an aluminium alloy similar to 2219-T6 Al were studied for $F=1 / 3,1 / 2$ and 1 .

(2) From the stress history profiles in spalled specimens recorded with carbon gauges, it was noticed that the differences between the first maximum stresses $\sigma_{1}$ and the first 
minimum stresses $\sigma_{2}$ in the stress history profiles of spalled specimens are roughly a constant in spite of the impact velocity and the stress duration. This may indicate a property which relates to the spallation characteristics of the material.

(3) The spallation damage of the aluminium alloy is in the form of brittle crack. The damage process involves nucleation, growth and coalescence of a large number of microcracks. Nearly all of the nucleation of the microcracks initiate at the second phase particles themselves.

(4) For a given impulse duration, there exists a threshold stress for nucleation. On the other hand, there is also a threshold time for nucleation for a certain stress amplitude. If the stress or the stress duration are less than their threshold values, no crack nucleation can be seen.

Acknowledgements - The authors are indebted to Li Tianyou, Chen Shuxia, Yang Daguang, Xu Suzhen, Mao Jiacheng and Xie Changchun for their valuable help and suggestions in accomplishing this work.

\section{REFERENCES}

1 T. W. Barbee, L. Seaman, R. Crewdoson and D. Curran, J. Mat. 7393 (1972).

2 D Curran, L. Seaman and D. Shockey, $J$ Phys. Today 30, 46 (1977)

3 F R. Tuler and B. M. Butcher, Int. J. Fract. Mech. 4, 431 (1968).

4. D. Curran, L. Seaman and D. Shockey, Phy's. Rep. 147, 253 (1987).

5. D. Shockey, L. Seaman and D. Curran, Int J. Fract Mech. 21, 145 (1985).

6. L Davison, A. Stevens and M. Kipp, J. Mech. Phys Solids 25, 11 (1977)

7. S. Cochran and D. Banner, J. Appl. Phy's. 48, 2729 (1977).

8. J. Johnson, J. Appl. Phys. 52, 2812 (1981).

9. A. Dremin and A. Moloders, Proc. Int. Symp. on Intense Dynamic Loading and Its Effects Science Press, Beijing, China, p $13(1986)$.

10. XING XIUSAN, Adr. Mech. 16, 495 (1987).

11. Bai Yilong, Ke Fuju and Luo Limin, J. Phys. Collque C3, Supplement au n 9. Tome 49 (1988), C3 215. (DYMAT 88).

12. Z. Rosenberg. G. Luttwak, Y. Yeshurun and Y. Partum, J. Appl. Phys. 54, 2147 (1983).

13. W ISBEll and D. Christman, AD 705536.

14 Zhao Shida, Shen Letian and Zhao Shuanglu, Acta Armamentarii 4, 49 (1985)

15. Shen Letian et al., Determination of Hugoniot for an aluminium alloy. Report of Institute of Mechanics, Chinese Academy of Sciences (1984).

16. M. A. MYers and L. E. MUIr (Editors), Shock Wave and High Strain Rate Phenomena in Metals Plenum Press, New York and London, p. 1048 (1981).

17 SHEN LETIAN et al., Determmation of spallation criterion for an aluminium alloy by plate impact experiments. Report of Institute of Mechanics, Chinese Academy of Sciences (1986).

18. Shen Letian, Bai Yilong and Zhao Shida, Proc. Symp. on Intense Dynamic Loading and Its Effects. Science Press, Beijing, China, p. 753 (1986).

19. B. Butcher, L. Barker, D. Munson and C. Lundergran, $A$ I AA J 2, 977 (1964).

20. Luo Limin, An experimental study of nucleation process and modelling of damage evolution in spallation in an aluminium alloy. MSc Thesıs, Institute of Mechanics, Chınese Academy of Sciences (1988). 